\title{
Delayed Epiphyseal Fusion
}

National Cancer Institute

\section{Source}

National Cancer Institute. Delayed Epiphyseal Fusion. NCI Thesaurus. Code C78267.

Abnormally late fusion of the bone growth plate. 